\title{
Introduction:
}

\section{Recent Research in Assessment in Education Abroad}

\section{Guest Editors:}

Kris Acheson

Katherine N. Yngve

Aletha Stahl

Lan Jin

Purdue University's Center for Intercultural Learning, Mentorship, Assessment and Research ${ }^{1}$

To prepare Frontiers' readership for the upcoming special issue on Assessment as Pedagogy, our editorial team has curated a virtual issue collection of key learning outcomes articles that have appeared throughout the decades of Frontiers' existence. In contrast with the inaugural virtual issue of this journal, our editorial struggle was, at first glance, that of dealing with an embarrassment of riches: We found over 75 articles that used a research-validated survey measure of learning outcomes. In total, this comes to more than 40 validated quantitative instruments!

It is a basic premise of both this virtual issue and the upcoming special issue of the Frontiers journal, however, that assessment differs from research and program evaluation. Assessment is usually defined as a multi-phase cycle of gathering, reflecting upon, and taking action on data, whose main purpose is to improve student learning (Maki, 2002; Salisbury, 2015). These phases include identifying the desired outcomes, identifying evidence of learning, collecting the evidence, analyzing and interpreting the evidence, making decisions or improvements based upon the evidence, and finally looping back to identifying desired outcomes of an improved learning intervention, course, or curriculum.

\begin{tabular}{ll} 
Category & Description \\
\hline Research & A truth-seeking activity that aims to uncover generalizable knowledge. \\
Program Evaluation & Seeks to establish the worth or impact of an intervention or program, often in comparison \\
& to a standard. \\
Assessment & Seeks primarily to improve student learning. May also, at the institutional or system level, \\
& wish to establish the effectiveness of efforts intended to produce student learning.
\end{tabular}

\footnotetext{
${ }^{1}$ www.purdue.edu/ippu/cilmar
}

Frontiers: The Interdisciplinary Journal of Study Abroad, Virtual Issue on Assessment in Education Abroad. (February 2020): pp. 1-6. 
Our first task in collating this virtual issue was to find a workable scholarly definition of the difference between assessment, research, and program evaluation. We began with a taxonomy from Lundquist (2019), summarized in the table above. The editorial team also agreed with Levy (2017) that the boundaries between the three are often fuzzy or overlapping; nonetheless, Lundquist gave us a valuable starting point.

In our preliminary review of articles, we excluded those that were primarily research-oriented. For example, if the study incorporated only a summative tool or an alumni survey, included a control group or an on-campus comparison group, or had a multi-institutional sample, we assumed the authors were searching for generalizable findings.

Distinguishing between program evaluation and assessment presented an additional challenge. To address it, we applied backward design principles, asking, "What is it important for Frontiers" readers to know so that they can use assessment as a pedagogy, and, after reading the virtual issue, what do we want them to be able to do?" Thus, our secondary inclusion strategy focused on exemplars within various facets of assessment, highlighting key issues of student-centered best practices (e.g., closing the loop, engaging faculty, equity-focused or culturally-competent assessment) as defined by NILOA, the National Institute on Learning Outcomes Assessment (https://www.learningoutcomesassessment.org/) and by ACPA's Commission on Assessment and Evaluation (https://www.myacpa.org/commae). In one case, this resulted in re-categorizing an article that had initially been categorized as "research" (and eliminated) because it included a control group.

Our efforts led to the selection of 11 exemplary articles on assessment in education abroad, grouped into three themes that help lay the foundation for the upcoming issue on Assessment as Pedagogy:

- Backward Design

- Institutional Impact

- Formative Assessment

\section{Backward Design}

"[] nstructional objectives, course design and implementation, and assessment must be inextricably linked; otherwise, the educational process is compromised."

$$
\text { -Dr. Alvino Fantini (2009), in Sage Handbook of Intercultural Competence }
$$

Popularized by Dee Fink, ${ }^{2}$ backward design is a process of developing or revising curriculum that begins with learning objectives before the selection of instructional techniques and assessment strategies (Wiggins \& McTighe, 1998). It is a pedagogical approach applied to assist educators in transfer of knowledge with a clear focus on learner-centered outcomes (Wiggins \& McTighe, 2005). Four articles were chosen to exemplify this important theme. For example, evaluating student ethnographic projects from 1986 to 1994, Jurasek, Lamson, and O’Maley (1996) outline the

\footnotetext{
${ }^{2}$ See www.deefinkandassociates.com.
} 
applications of ethnography on study abroad programs in assessing student learning. They assume that "ethnographic field learning is a matter of processes as much as it is about outcomes," and suggest further research to explore the learning processes. With the purpose of transforming the study abroad experience into a valuable academic experience, Montrose (2002) discusses how to use the Learning Objectives Matrix to assess experiential learning by articulating intentional core learning outcomes. In addition, DiBiasio and Mello (2004) employ a multilevel assessment process program, advisor, and external level - so as to deeply understand student learning and improve the program. Finally, Engle (2013) examines over 50 qualitative questionnaires from universities for study abroad programs, suggesting that meaningful assessment should complete a circle from mission statement to program implementation and design, then to student learning, and finally to assessment evaluation. ${ }^{3}$ To sum up, these articles emphasized the importance of planning programs/courses with clear intentions and using a variety of assessment tools to assess student learning. Articles in this thematic category focus on "assessment of learning" more than assessment as pedagogy - that is, they are concerned with documenting learning that did or did not occur in a backward-designed curriculum, with decisions made based upon this data to subsequently improve the program or course.

\section{Institutional Impact}

"Assessment is a process that should situate improvement as its primary intended outcome. Organizations and institutions that fail to introduce changes based on assessment findings have not really assessed."

—Dr. Mark Salisbury (2015), in Brewer \& Savicki (Eds.), Assessing Study Abroad

At the institutional or system level, assessment of learning ideally serves as important evidence of continuous quality improvement. As such, it marries to some extent all three purposes of learning outcomes inquiry (e.g., research, program evaluation, and a focus on improving student learning, also known as assessment). This blend of purposes is often essential for persuading decision-makers in higher education to take action. This theme of the virtual issue showcases three exemplars. We include the GLOSSARI Project article (Sutton \& Rubin, 2004), although tilted strongly towards our definition of research, because it reports on the initial stages of a system-wide effort to "assess the student learning outcomes from studying abroad." Next, as educational leadership increasingly focuses on equity and assessment, ${ }^{4}$ we felt compelled to include the recent article by Wick, Willis, Rivera, Lueker, and Hernandez (2019) in order to highlight an asset-based framework for seeking to understand both the learning experience of a non-dominant student population and the institutional impact of education abroad on the hosting community. Finally, institutions that support faculty-led study abroad often hope that program leaders will be able to "transfer" their own learning moments to the on-campus setting, thus impacting students who likely

\footnotetext{
${ }^{3}$ These best practices are echoed in the Forum on Education Abroad's (2015) Standards of Good Practice for Education Abroad, in particular Standard 1, which encourages cycles of continuous improvement connected to missions and goals, and Standard 2, which draws attention to the assessment of student learning. See https://forumea.org/resources/standards-of-good-practice/ for more information.

${ }^{4}$ See https://www.learningoutcomesassessment.org/equity/
} 
will never engage in education abroad. To address this definition of institutional impact, we include Ellinghaus, Spinks, Moore, Hetherington, and Atherton's (2019) comparative case study of how professors' leadership of study abroad has affected their classroom teaching. In summation, we note that each of these three articles is, at the moment, sui generis: Very few of the articles we reviewed focused on institutional effectiveness as anything other than graduation, retention, career placements and/or GPA. Choosing to define success via such outputs is common - and valuable to institutions - but it is more aligned with program evaluation than with evidence-based pedagogies, which focus more on learning outcomes. In short, as with the articles illustrating the backward design theme, articles featured in this thematic category are most accurately described as "assessment of learning" rather than assessment as pedagogy, although clearly the scope is larger here than with the previous group of studies.

\section{Formative Assessment}

"People don't learn from experience ... The truth is that people learn from reflecting on their experience."

- Dr. Sivisailam “Thiagi” Thiagarajan (2019), SIETARUSA Blog “Thiagi Tips”

The final theme, formative assessment, is understood as assessment that takes place before or during the learning process with the goal of improving that process and its outcomes. This is often referred to, at least by K-12 teachers, as assessment for learning (Heick, 2019) because instructors or course designers collect and analyze data so as to modify course content or methodology for the purpose of enhancing learning outcomes. Among our collected articles in this theme, for example, Paige, Cohen, and Shively (2004) use a combination of qualitative and quantitative data to understand the effects of language and cultural interventions on student intercultural sensitivity and their reported culture and language strategies. Similarly, Savicki, Adams, Wilde, and Binder (2008) point explicitly to pedagogical implications in their study of how phenomena related to intercultural adjustment are experienced distinctly at different points in the course of a program. However, when assessors also provide feedback to learners themselves in a way that supports growth and development by providing motivation or direction, this approach might be better described as assessment as learning; in this case, assessment becomes integral to the very process of learning. In Frontiers to date, the former is much more common than the latter, but some exemplars here do illustrate this approach. Pagano and Roselle (2009) push beyond traditional ideas of reflection with the idea of refraction - integration and elaboration of the experience through an examination of assumptions - as a pedagogical intervention. Finally, noting the mismatch between language proficiency and intercultural competence, Engelking (2018) develops the use of critical incidents to build the intercultural competence in the language classroom, while making specific reference to the use of an assessment instrument to drive pedagogical approaches. In short, articles in this formative assessment theme group demonstrate how assessment can be used to inform the learning process mid-stride by providing information about learner readiness and progress to instructors so that they may shape pedagogy responsively. In the best cases, these models also showcase how to provide opportunities for students themselves to leverage assessment results and/or the assessment process to maximize their learning. 


\section{Upcoming Special Issue on Assessment as Pedagogy}

These selected 11 articles on assessment in education abroad, categorized into the three themes of Backward Design, Institutional Impact, and Formative Assessment, provide a foundation of scholarship for the upcoming Frontiers issue on Assessment as Pedagogy. To reiterate our basic premise, assessment is, at its heart, a pedagogical cycle of gathering, reflecting upon, and taking action on data, in order to improve student learning. Done right, assessment provides an operational roadmap for inclusive excellence - meaning that it takes into account contextual factors such as learners' differing preparedness, aptitudes, and motivations, instructors' skill in implementing curriculum, and other factors that impact the extent to which individual students achieve intended learning outcomes. When instructors engage fully in this cycle, they are doing both assessment $\boldsymbol{o f}$ and for learning. When they involve students in reflection about their assessment results and encourage them to autonomously plan for individualized learning based on those results, this also becomes assessment as learning (Rowe, 2012).

In the education abroad literature, there is a scarcity of work that fully addresses the potential of assessment as we discuss it above. Few published articles talk about the alignment of method and instrument(s) with learning objectives and course assignments that occurs in backward design, or about formative assessment methods such as low-stakes, individualized goal setting and feedback loops. Likewise, extensive searches reveal only one article (Krishnan et al., 2017) that describes an iterative process of moving from assuming the effectiveness of immersion-oriented program structures to creating learner-centered, deep reflection about the opportunities provided by that program structure.

Having come so far in recognizing the benefits of assessment in general, the field of education abroad now needs a clearly delineated set of evidence-based best practices specifically for employing assessment pedagogically. Also necessary are models that education abroad professionals can follow to put principles into practice. With this special issue, the editorial team aims to answer these needs as well as suggest remaining gaps in the literature and directions for additional future research.

In short, the upcoming special issue of Frontiers will focus on the overarching question: "How can institutions and instructors employ research-based best practices of 'assessment as learning' to help education abroad students achieve intercultural and/or disciplinary learning outcomes more effectively?" We particularly solicit articles that address the following gaps in education abroad scholarship:

1. The extensive or systematic use of formative assessment instruments and practices

2. Strategic intentionality in assessment for or as learning at the institutional level

3. Exemplars of particular instruments that work well for assessment as learning

4. Models for scaling up pedagogical uses of assessment to larger groups of students

5. Iterative applications of backward design principles (i.e., multi-year program revisions)

6. Extended longitudinal assessment designs 
7. Interdisciplinary discussions that recommend or apply assessment practices/frameworks from other domains to education abroad

The issue will present cutting-edge empirical studies and theoretical reflections that uphold assessment as a learner-centered pedagogy that is integral to the learning-mentoring-teaching process. We look forward to collaborating with the Frontiers community in advancing the scholarship on this valuable professional practice for education abroad.

\section{References}

Fantini, A. E. (2009). Assessing intercultural competence. In D. Deardorff (Ed.), The SAGE handbook of intercultural competence (pp. 456-476). Thousand Oaks, CA: SAGE.

Heick, T. (2019, December 12). The difference between assessment of learning and assessment for learning [Web log message]. Retrieved from https://www.teachthought.com/pedagogy/thedifference-between-assessment-of-learning-and-assessment-for-learning/

Krishnan, L. A., Masters, C., Holgate, H., Wang, C., \& Calahan, C. A. (2017). Structured study abroad enhances intercultural competence. Teaching and Learning in Communication Sciences \& Disorders, 1(1), 1-26. doi: https://doi.org/10.30707/TLCSD1.1Krishnan

Levy, J. (2017, February 14). How to differentiate assessment, evaluation and research [Web log message]. Retrieved from https://www.presence.io/blog/how-to-differentiate-assessment-evaluationresearch/

Lundquist, A. (2019). Assessment, evaluation and research: Relationships and definitions in the field of student affairs. ACPA Students Affairs Assessment Institute: Toronto, CA. Retrieved from https://baselinesupport.campuslabs.com/hc/en-us/article_attachments/115017881466/AER-

Definitions-Handout-Module-1.pdf

Maki, P. L. (2002). Developing an assessment plan to learn about student learning. The Journal of Academic Librarianship, 28(1-2), 8-13. doi: https://doi.org/10.1016/S0099-1333(01)00295-6

Rowe, J. (2012). Assessment as learning. Retrieved from http://etec.ctlt.ubc.ca/510wiki/Assessment_as_Learning

Salisbury, M. (2015). How we got to where we are (and aren't) in assessing study abroad learning. In V. Savicki \& E. Brewer (Eds.), Assessing study abroad: Theory, tools, and practice (pp. 15-32). Sterling VA: Stylus.

Sivisailam, T. (2019, May 14). Thiagi tips: Some thoughts on debriefing [Web log message]. Retrieved from: https://www.sietarusa.org/blog/7341594

The Forum on Education Abroad. (2015). Standards of good practice for education abroad (5th ed.). Carlisle, PA: The Forum on Education Abroad. Downloaded from https://forumea.org/wpcontent/uploads/2014/08/Standards-2015.pdf

Wiggins, G., \& McTighe, J. (1998). Understanding by design framework. Alexandria, VA: Association for Supervision and Curriculum Development. Retrieved from https://www.ascd.org/ASCD/pdf/siteASCD/publications/UbD_WhitePaper0312.pdf

Wiggins, G., \& McTighe, J. (2005). Understanding by design (2nd ed.). Alexandria, VA: Association for Supervision and Curriculum Development. Retrieved from https://pdfs.semanticscholar.org/1da0/0ce969945341d7e886c347341c7b9bea8994.pdf 